\section{Automated retinotectology}

The retunotectal projection has been the principal battleground, since the 1930s, for the experimental investigation of the factors determining specific neural connections Since the late 1950s, the electrophysiological determination of the retinotectal map has been the dominant expertmental method. Many of the conclusions derived with this method have been questioned (by other investigators using the same method), and some of these disputes remain unresolved even today Recently, Davld Northmore and his associates have developed two automated methods for assessing retınotectal function which are described below In different ways, these methods correct some of the defictencies of the old method

There are at least two difficulties with the standard retinotectal mapping procedure The first is that the microelectrode in the tectum records electrical activity which, as everyone agrees, does not necessarily originate from tectal cells This is not a fatal flaw; even if the electrical activity is assumed to be presynaptic, it reveals where the axons are arborized, and this is not trivial. Even so, one would like to know if synapses are established The second problem is the low signal to noise ratio in most experimental tecta This is probably a consequence of the fact that regenerated and sprouted axons are physically smaller than the original processes, and therefore give smaller action currents Many of the points in a map may have been decided by the experimenter with some uncertainty, but none of this doubt comes across in the published map In other words, the experimental results are in fact well digested and filtered by the observer, and so readers of the work, who may well have a different set of biases, suspect that they might have obtained a different map, under the same conditions

The first of these difficulties is a technical one, and could be overcome by the development of a method sensitıve only to postsynaptıc activity, an automated method of behavioral penmetry is one answer' The second difficulty is more a matter of personal intuition and mistrust, about the only. technical fix here is to display the results in a less digested form, or else to make the decision-making unquestionably objective. Northmore and Masıno2 have opted for the latter

Behavioral perimetry has been used to assess the retinotectal projection for many years The behavioral signs of vision, such as the optomotor response to a rotating striped drum, or the orientation response to a prey object, establish that vision has returned, but they indicate nothing about where in the brain the signalling fibers have projected. Sperry ${ }^{3}$ combined exper1mental surgery with the orientation response to establish that the retina's projection to the tectum was the important one, and he showed that it was spatially ordered, what the order was, and that the regenerated order

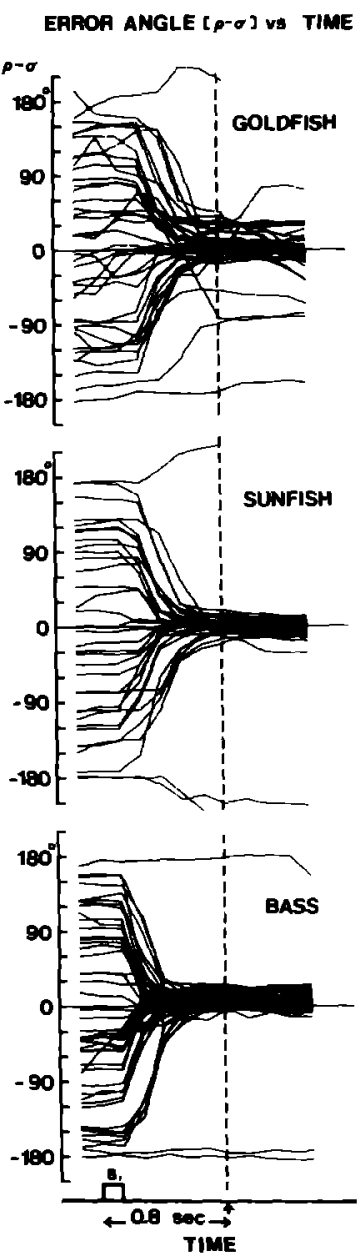

Fig. 1 The left column shows the error angle, the difference between the fish s ortentation and the target, as a function of time By convention, the inttal error is positive for stimuli in the left field, negative in the right The right column shows the final response angle (vertically) is the stimulus angle (horizontally) Each point is one trial The dashed diagonal lines show perfect behovior The soltd line is a running wetghted median of the data The points to the right of the boxes show the results of dummy trials, which were conducted, without prevtous stimult, when the fish was centered (Reproduced, with permission, from Ref 1 )

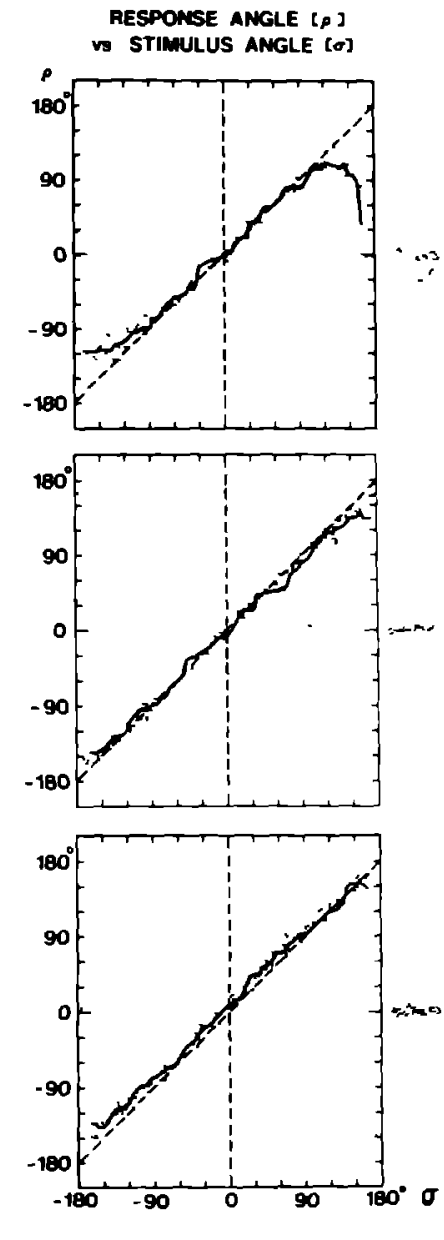

resembled the onginal order $\mathrm{He}$ did this by ablatıng either the caudal, dorsal, or rostral quadrant of the tectum in frogs (The ventral quadrant was surgically inaccessible.) Following this surgery, the anımal was then presented with prey, and was found to have regional blind spots For example, after the caudal lesion, the frog oriented to prey presented overywhere except in the posterior field of the eye contralateral to the surgery. This was interpreted to mean that the retınal axons with receptive fields in the posterior field - those in nasal retına no longer contacted the tectal cells responsible for the onientation response. Analogous results were obtained for different parts of the visual field after the other lesions. When sımılar lesions were made in frogs with

(C) 1985 Elyevier Science Publıshers B V Amsterdum (1777- - 5912/85/802 OO 
regenerated optic nerves, the same lesions produced the same scotomata as in normals, evidence that the regenerated projection resembled the onginal More recently, others have used slightly different behavioral methods to assess visual function in fish $^{4,5}$, but both of these required that the animal be restrained, whereas the 'automated behavioral perimetry' is carried out on freely-swimming anımals.

The aim is to have the fish indicate that it sees a target, the location of which is set by the experimenter The fish swims in a cylındrical arena with equally spaced light-emitting-diodes on the walls The fish is trained to orient toward a light when it turns on. With the use of a minicomputer to control the presentation of the stimuli and the collection of data, a large number of trials was possible The computer turned on the stımulus, very briefly, and then analysed a video record of the fish's activity. This record was obtained from a video camera which viewed the fish from below, in silhouette The analysis involved recognizing which end of the fish was the front, and then fitting a straight arrow through the fish's profile, thus establishing where it pointed. Fig 1 shows some results, and two conclusions are evident First, the method works impressively well, as it produces results with very small variability on a completely unrestrained animal Secondly, it shows that the fish has an absolute sense of spatial position, since the stımulus was illuminated so bnefly that the fish had not even begun to orient before the light went out Therefore the fish could not have servoed in on the target, but instead made a ballıstic movement

The method was valıdated further by crushing one optic nerve, which resulted in the expected lack of an orientation response to that side, and by removing the caudal half of the tectum on one side This abolished responses to stimuli in the posterior field on the contralateral side, as Sperry's results on frogs predicted But since 1970, it has been known that when the caudal hemitectum is removed and the optic nerve severed, the projection from the entire retina compresses into the tectal remnant ${ }^{6}$ Northmore $^{7}$ reproduced this result behaviorally, as Fig 2 illustrates, confirming an earlier behavioral study $^{5}$ Moreover, since the response depended on accurate motor behavior.

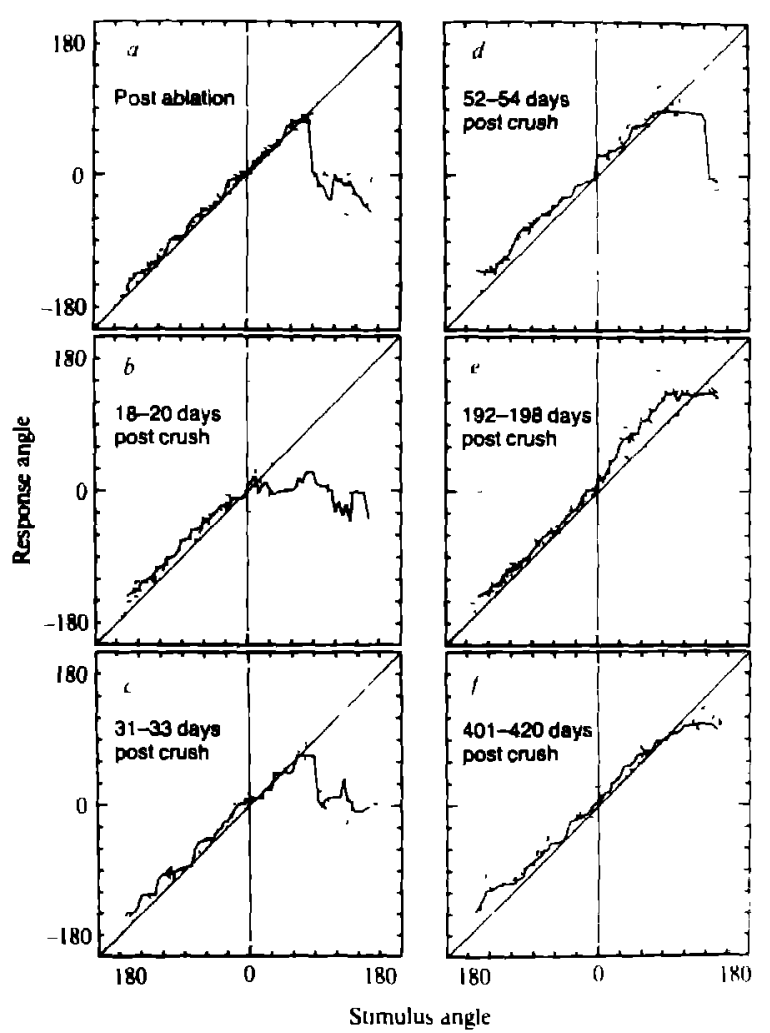

Fig. 2. Similar to the nght column in Fig. 1 The caudal half of the left tectum was ablated, and the data in panel A obtaned Thirteen days later, the right optic nerve was crushed, and partels B-F were obtained thereafter Note that the caudal right field was inthally neglected, but gradually filled in to approximate the normal case (Reproduced, with permission, from Ref 7 )

the result demonstrated that the tectal 'motor map' was not fixed anatomically, but must also be modifiable as the sensory map was known to be

Most recently, visuomotor per1metry has been supported by parallel automated electrophysiological maps. ${ }^{2}$ As usual, the fish is immobilized, and the expenmenter inserts a microelectrode into a tectal location. But in contrast to the usual, the expenmenter then turns the decision-making over to a computer The computer moves visual stimulı around the visual field, records the electrical responses to each stimulus location, and then decides where the receptive field is, on the basis of which locations evoked the biggest response. Of course, this is the same procedure that is ordinanly carned out by the expenmenter, using his or her own hands and sensory apparatus, but the objective aspect of the decision makıng removes any suspicion of bias from the final result There were no surprises in this expenment, the objectively derived map was similar to those acquired by more conventional means One supposes that when the technique is applied to expenmentally altered projections, there will be less reason to doubt the results, given that the computer is free of prejudice

In recent years, the field of retınotectology has shed its earlier reputation as a contentious 'random nosse generator' (a description once offered at a meeting). The introduction of modern anatomical techruques and now, automated behavioral and electrophysiological ones, should further assist this metamorphosis.

\section{Selected references}

1 Northmore, D P M, Skeen, L C and Pindzola J M (1981) Visıon Res 21, 843854

2 Northmore, D P M and Masino, T (1984) Exp Neurol 84, 109-125

3 Sperry, R W (1944) J Neurophysiol 7, 5769

4 Schwassmann, H O and Krag, M H (1970) Vtsion Res 10, 29-42

5 Scott, M Y (1977) Exp Neurol 54, 579-590

6 Gaze, R M and Shamm S, C (1970) Exp Brain Res 10, 171-181

7 Northmore, D P M (1981) Nature (London) 293, $142-144$ Michigan, Ann Arbor, MI 48I09, USA 


\section{The primate social environment, brain neurochemical changes and psychopathology}

Changes in cerebrospinal fluid (CSF) neurochemical measures associated with both depression and schizophrenia have been reported and replicated in several studies Nevertheless, the causes of these changes remain uncertain Neurochemical differences may be secondary effects of behavioral changes, altered diet, dailly routine, and perhaps drug use Alternattvely, if neurochemical changes prodice a behavtoral disorder, then a further question arses as to what caused these changes in the first place Recent animal studies suggest that disruption of social development or ongoing soctal relationships could cause some of these changes.

There are a considerable number of neurochemical studies of human patients which focus on the catecholamine (CA) and indoleamine neurotransmitter biosynthetic and degradative pathways In the CA pathway, the amıno acid precursor, tyrosine, is converted to dopamine (DA) DA is then converted to norepinephrine (NE) In primates the najor metabolite of DA is homovanillic acid (HVA), and the major metabolite of $\mathrm{NE}$ is 3-methoxy-4-hydroxyphenylethylene glycol (MHPG) The precursor of the indoleamine neurotransmitter, serotonin (5-hydroxytryptamıne, [5-HT]) is tryptophan Its major metabolite is 5-hydroxyindoleacetic acid (5-HIAA) Measures of NE, HVA and 5-HIAA in CSF samples obtained from the cerebral ventricular system, or from the cisterna magna, are correlated with activity in periventricular brain neuronal mechanisms in nonhuman primates Similar but less robust relationships can be demonstrated in CSF obtained at the lumbar region of the spinal cord in humans ${ }^{12}$

The consistency of the relationship between changes in lumbar CSF neurochemicals and changes in behavior appears to be most potent in humans with higher CSF NE or lower CSF 5-HIAA concentrations than controls Elevated CSF NE is associated with mania, anxious depression, and paranoıd schizophrenıa ${ }^{2,3}$ Reduced CSF 5-HIAA is associated with interpersonal violence and suicide Studies of men with histories of violent aggression have related increased aggression to low concentratıons of CSF 5-HIAA ${ }^{45}$ Suicide attempts by patients with low 5-HIAA are more frequent and more violent ${ }^{6}$ In a follow-up study, Traskman-Benz et al ${ }^{7}$ found that 6 out of 30 patients with CSF 5-HIAA values below the median of a 119 patient sample had committed suicide within one year of discharge from the hospital The cause of increased CSF NE or reduced 5-HIAA in humans remans obscure However, five major factors that affect neurotransmitter and metabolite concentrations in CSF have been identıfıed in human and nonhuman pnmates They are.

(1) Time of day Several neurotransmitters and metabolites have diurnal rhythms in nonhuman primates Among these are NE, DA, 5-HT, and HVA CSF CA rhythm parallels wakefulness, activity, and body temperature, and is out of phase with 5-HT, cortisol, prolactın and testosterone ${ }^{8.9}$

(2) Precursor avallability Serotonın systems are affected by intake of precursor amıno acids CSF 5-HIAA increases with increased dietary tryptophan in humans ${ }^{10}$. CSF 5-HIAA is correlated with plasma tryptophan in vervet monkeys (Cercoputhecus aethops) and correlations are higher in males than females ${ }^{11}$ Dietary amınes do not affect CSF NE concentrations in humans ${ }^{12}$

(3) Gender CSF 5-HIAA, HVA and MHPG concentrations are lower in male adult (feral reared) vervets ${ }^{11}$ In humans, gender differences have been reported in some studies ${ }^{13}$ but not others ${ }^{14}$ Of the variety of factors that can effect CSF neurochemical measures, most of them appear to have a greater impact on males $11,13,14$

(4) Development HVA is higher in human infants and juveniles than in adults Developmental curves are most prominent in males CSF HVA declines to adult levels by approximately 25 years of age ${ }^{14}$.

(5) Social environment Over and above the aforementioned factors, social interactions can markedly and persistently alter measures of neurotransmitter metabolism in nonhuman primates

The quality of early social rearing expenence produces differences in brain NE system function that lasts into adulthood in rhesus monkeys (Macaca mulatta) $)^{15}$ Increased NE system activity has been related to anxious behavior ${ }^{16}$, and CSF NE concentrations may predict individual behavioral responses to social stressors Increased CSF NE is associated with active or aggressive responses to social stressors ${ }^{15}$

Several studies suggest that 5-HT mechanisms influence social interactions in nonhuman primates, and reciprocally, that social interactions affect 5-HT mechanisms Early social separation and solation in both human and nonhuman primates causes reductions in platelet 5-HT which return to normal when social interactions are restored ${ }^{17}$ Blood and CSF measures are positively correlated, especially in males ${ }^{11}$. Social domınance in male vervets, $1 \mathrm{e}$, receiving deference from other males, is a primary social regulatory mechanism for aggression Dominance is positively correlated with CSF 5-HIAA and whole blood 5-HT (WBS) concentrations $^{18}$ Changes in male social dominance, whether naturally occurring, or experimentally induced, have a reciprocal effect on 5-HT mechanisms Dominant vervets have WBS levels twice as high as subordinates, and these levels drop if dominance is lost ${ }^{19}$

Social environment may affect CSF NE, HVA and 5-HIAA concentrations in humans as well Repeated episodes

TABLE I. Factors currently associated with changes in CSF norepinephrine and 5-hydroxyındoleacetic acid concentration in human and nonhuman primates

\begin{tabular}{lll}
\hline CSF neurochemical & $\begin{array}{l}\text { Association and direction of concentration change } \\
\text { Nombuman }\end{array}$ \\
\hline Norepinephrine & $\begin{array}{l}\text { mania } \uparrow \\
\text { paranoid schizophrenia } \uparrow \\
\text { dnxious depression } \uparrow \\
\text { duration of hospitalizdtion } \uparrow\end{array}$ & $\begin{array}{l}\text { social stressors } \uparrow \\
\text { irritable aggression } \uparrow \\
\text { agitation } \uparrow \\
\text { circadian rhythm (day } \uparrow, \text { night } \downarrow \text { ) }\end{array}$ \\
$\begin{array}{l}\text { 5-hydroxyındole-acetıc } \\
\text { acid (5-HIAA) }\end{array}$ & $\begin{array}{l}\text { sucide? } \\
\text { violence } \downarrow \text { (when patred } \\
\text { with NE } \uparrow)\end{array}$ & suborial dominance $\uparrow$ \\
& repeated affective illness $\downarrow$ & \\
\hline
\end{tabular}

